\title{
Isolation of Klebsiella pneumoniae from Sungai Skudai and in silico analysis of putative dehalogenase protein
}

\author{
Nur Aina Jamil' ${ }^{1}$ Roswanira Abdul Wahab², Amir Husni Mohd Shariff ${ }^{3 *}$ and Fahrul Huyop ${ }^{1 *}$ \\ ${ }^{1}$ Department of Biosciences, Faculty of Science, Universiti Teknologi Malaysia, 81310 UTM Johor Bahru, Malaysia. \\ ${ }^{2}$ Department of Chemistry, Faculty of Science, Universiti Teknologi Malaysia, 81310 UTM Johor Bahru, Malaysia. \\ ${ }^{3}$ Faculty of Food Science and Nutrition, Universiti Malaysia Sabah, Jalan UMS, 88400, Kota Kinabalu, Sabah, Malaysia. \\ Email: amir.husni@ums.edu.my and fahrul@utm.my
}

Received 25 September 2020; Received in revised form 15 December 2020; Accepted 11 March 2021

\begin{abstract}
Aims: The surplus use of herbicide Dalapon ${ }^{\circledR}$ contains 2,2-dichloropropionic acid (2,2-DCP) poses great danger to human and ecosystem due to its toxicity. Hence, this study focused on the isolation and characterization of a dehalogenase producing bacteria from Sungai Skudai, Johor, capable of utilizing 2,2-DCP as a carbon source and in silico analysis of its putative dehalogenase.

Methodology and results: Isolation of the target bacteria was done by using 2,2-DCP-enriched culture as the sole carbon source that allows a bacterium to grow in $20 \mathrm{mM}$ of $2,2-\mathrm{DCP}$ at $30{ }^{\circ} \mathrm{C}$ with the corresponding doubling time of $8.89 \pm 0.03 \mathrm{~h}$. The isolated bacterium was then designated as Klebsiella pneumoniae strain YZ based on biochemical tests and basic morphological examination. The full genome of $K$. pneumoniae strain KLPN 25 (accession number: RRE04903) which obtained from NCBI database was screened for the presence of dehalogenase gene, assuming both strains YZ and KLPN_25 were the same organisms. A putative dehalogenase gene was then identified as type II dehalogenase from the genome sequence of strain KLPN_25. The protein structure of the type II dehalogenase of KLPN_25 strain was then pairwise aligned with the crystal structure of L-2-haloacid dehalogenase (L-DEX) Pseudomonas sp. strain $\mathrm{YL}$ as the template, revealing the existence of conserved amino acids residues, uniquely known to participate in the dehalogenation mechanism. The finding thus implies that the amino acid residues of type II dehalogenase possibly shares similar catalytic functions with the L-DEX.

Conclusion, significance and impact of the study: In conclusion, this study confirmed the presence of new dehalogenase from the genus Klebsiella with potential to degrade 2,2-DCP from the river water. The structural information of type II dehalogenase provides insights for future work in designing haloacid dehalogenases.
\end{abstract}

Keywords: 2,2-DCP, degradation, dehalogenase, Klebsiella pneumoniae, halogenated compound, type II dehalogenase

\section{INTRODUCTION}

The advancement of technology has resulted in the formation of synthetic compounds known as xenobiotics which can cause environmental pollution when present in high concentration. Their ubiquitous distribution in this biosphere is due to extensive usage in industry and agricultural activity (Jing and Huyop, 2008; Oyewusi et al., 2021). Apart from its widespread use as pesticides, insecticides and antibiotics (Abel et al., 2012), these manmade compounds are frequently found in herbicides as agrochemicals used to prevent the growth of undesired weeds. 2,2-dichloropropionic acid (2,2-DCP) often market as Dalapon, is a synthetic halogenated chemical extensively used as an active compound in the production of herbicides in controlling a wide variety crops (Ismail et al., 2016). 2,2-DCP is a plant growth regulator that have been used in controlling specific annual and perennial grasses, such as quick grass, Johnson grass, Bermuda grass as well as rushes and cattails (Jing and Huyop, 2008).

However, the implementation of chemically synthesized herbicide in agricultural fields can cause negative environmental problems. Rivers and lakes become polluted by herbicide due to its persistence and resistance in nature. The bioaccumulative of these compounds and their toxicity are threat to human health and environment (Fetzner and Lingens, 1994). The accumulation of 2,2-DCP due to its resistance to degradation has led to river water pollution and has adverse effect on aquatic habitat.

Recently, microbial degradation of toxic compounds has become a prominent path to transform toxic compounds into harmless products. A large number of 
dehalogenases producing bacteria have been previously isolated, purified and characterized by widely distributed microorganisms that utilize halogenated compounds as their primary sources of carbon and energy (Ismail et al., 2016; Heidarrezaei et al., 2020; Oyewusi et al., 2020; Wahhab et al., 2021). The enzyme possessed by the microbes to detoxify harmful halogenated compounds has also been well studied (Huyop and Nemati, 2010; Hamid et al., 2011; Adamu et al., 2020). The halogenated compounds are degraded by dehalogenases synthesize by bacteria through dehalogenation process which catalyze the cleavage of carbon-halogen bond (Fetzner, 1998; Alomar et al., 2014). Their capability in removing pollutants helps reduce the environmental halogenassociated pollution.

To combat environmental problems, biological method is a suitable choice as various halogenated degrading bacteria have been studied in the last few years. However, there are limited research on bacteria isolated from river water samples that able to degrade 2,2-DCP. Therefore, the main objective of this study is to isolate 2,2-DCP degrading bacteria from Sungai Skudai river water. The isolated bacterium that capable in degrading 2,2-DCP was further characterized. Besides, the genetic properties of the isolated bacterium were analyzed based on the genome sequence of the similar bacterium genus and species available from the National Centre for Biotechnology Information (NCBI) database.

\section{MATERIALS AND METHODS}

\section{Media preparation}

A total of $0.5 \mathrm{~L}$ of stock solution of "Paul John Chapman" or 10× PJC basal salts (containing $16.22 \mathrm{~g} \mathrm{~K}_{2} \mathrm{HPO}_{4}, 5.0 \mathrm{~g}$ $\mathrm{NaH}_{2} \mathrm{PO}_{4} \cdot 2 \mathrm{H}_{2} \mathrm{O}$ and $\left.12.5 \mathrm{~g}\left(\mathrm{NH}_{4}\right)_{2} \mathrm{SO}_{4}\right)$ and $10 \times \mathrm{PJC}$ trace metals (containing $0.5 \mathrm{~g}$ nitrilotriacetic acid, $1.0 \mathrm{~g}$ $\mathrm{MgSO}_{4} \cdot 7 \mathrm{H}_{2} \mathrm{O}, 0.06 \mathrm{~g} \mathrm{FeSO}_{4} \cdot 7 \mathrm{H}_{2} \mathrm{O}, 0.015 \mathrm{~g} \mathrm{MnSO}_{4} \cdot 4 \mathrm{H}_{2} \mathrm{O}$ and $0.015 \mathrm{~g} \mathrm{ZnSO}_{4} \cdot \mathrm{H}_{2} \mathrm{O}$ ) were prepared (Hareland et al., 1975; Heidarrezaei et al., 2020). The growth media contained $10 \mathrm{~mL}$ of $10 \times$ basal salts and $10 \mathrm{~mL}$ of $10 \times$ trace metals per $100 \mathrm{~mL}$ of distilled water and were autoclaved at $121{ }^{\circ} \mathrm{C}$ for $5 \mathrm{~min}, 15 \mathrm{psi}$. Sodium 2,2dichloropropionate $(2,2-\mathrm{DCP})(1 \mathrm{M})$ stock solution was prepared by dissolving $1.65 \mathrm{~g}$ of sodium 2,2-DCP in 10 $\mathrm{mL}$ of distilled water and filter-sterilised (with $0.2 \mu \mathrm{m}$ pore size of nylon filter. Then, the 2,2-DCP stock solution was added aseptically into the growth media to get the desired final concentration. As for solid minimal media preparation, Oxoid bacteriological agar $(1.5 \% \mathrm{w} / \mathrm{v})$ was added prior sterilization.

The bacteria were also allowed to grow in $20 \mathrm{mM}$ pyruvate growth solution containing $10 \mathrm{~mL}$ of each $10 \times$ basal salts and trace metals in $100 \mathrm{~mL}$ of distilled water. Pyruvate $(1 \mathrm{M})$ stock solution was prepared by dissolving $5.5 \mathrm{~g}$ of sodium pyruvate in $50 \mathrm{~mL}$ distilled water and filter-sterilised using $0.2 \mu \mathrm{m}$ pore size of nylon filter. An approximately $2 \mathrm{~mL}$ of pyruvate stock solution was added aseptically into the growth media.

\section{Bacteria cultivation}

River water sample was collected from Sungai Skudai, Johor Bahru, Malaysia. About $3 \mathrm{~mL}$ of water sample was added into $100 \mathrm{~mL}$ liquid PJC minimal medium containing $20 \mathrm{mM}$ of 2,2-DCP and incubated at $30^{\circ} \mathrm{C}$ overnight in a rotary shaker set at $150 \mathrm{rpm}$. A bacteria culture $(0.1 \mathrm{~mL})$ was spread onto solid PJC minimal media supplemented with $20 \mathrm{mM}$ of 2,2-DCP and incubated at $30^{\circ} \mathrm{C}$ for next 7 days. The potential bacterial isolates that grow were selected and transferred onto a fresh PJC minimal media supplemented with the same media component to obtain pure culture.

A single colony of the bacterium was then inoculated into a $100 \mathrm{~mL}$ liquid minimal medium containing $10 \mathrm{mM}$ of 2,2-DCP and incubated at $30^{\circ} \mathrm{C}$ overnight to prepare for the inoculum. After an overnight incubation period, the inoculum ( $25 \mathrm{~mL}$ from the overnight culture at $A_{680 \mathrm{~nm}} 1.2$ ) was then inoculated into a fresh PJC liquid minimal media containing $10 \mathrm{mM}, 20 \mathrm{mM}, 30 \mathrm{mM}$ and $40 \mathrm{mM}$ concentrations of 2,2-DCP, respectively and $20 \mathrm{mM}$ of pyruvate served as control. The cultures were prepared in triplicates and incubated at $30{ }^{\circ} \mathrm{C}$ for $24 \mathrm{~h}$ on a rotary shaker at $150 \mathrm{rpm}$. The cells doubling time was determined by checking the turbidity at $A_{680 n m}$ at specific time intervals quantitated based on changes in the turbidity from the initial time.

\section{Bacteria characterization}

A standard Gram-staining procedure was performed. The basic biochemical tests were based on standard API-20E test kit for bacteria identification according to Bergey's Manual of Systematic Bacteriology (Holt et al., 1994).

\section{Database screening for the genome sequence belongs to $K$. pneumoniae}

The basic biochemical tests proposed strain $Y Z$ belongs to the genus $K$. pneumoniae. Therefore, all $K$. pneumoniae in the NCBI database were screened for dehalogenase gene in their full genome sequence assuming that strain $\mathrm{YZ}$ and other/selected Klebsiella sp. in the data base will carry similar gene in the genomes.

\section{Computational analysis}

\section{Dehalogenase amino acid sequence}

Klebsiella pneumoniae strain KLPN_25 selected from the $\mathrm{NCBI}$ database (https://www.ncbi.nlm.nih.gov/) with accession number RRE04903 was found to carry putative dehalogenase gene that belongs to haloacid dehalogenase type II. The amino acid sequence was then retrieved in FASTA format for further analysis. The sequence was subjected to ProtParam analysis via Expasy (Expert Protein Analysis System) Proteomic Server (https://web.expasy.org/protparam/) for primary structure analysis (Gasteiger et al., 2005; Harisna et al., 2017). A NCBI-BLASTp (Altschul et al., 1990) of the 
Malays. J. Microbiol. Vol 17(3) 2021, pp. 294-304

DOI: http://dx.doi.org/10.21161/mjm.201012

amino acids of the haloacid was performed and five similar dehalogenase proteins from various species of dehalogenase producing bacteria were matched to putative dehalogenase belongs to $K$. pneumoniae strain KLPN_25.

\section{Multiple sequence alignment}

The multiple amino acid sequence alignment was carried out using MultAlin web-based sequence alignment at http://multalin.toulouse.inra.fr/multalin/ (Corpet, 1988).

\section{Secondary structure prediction}

The secondary structure prediction for haloacid dehalogenase type II of $K$. pneumoniae strain KLPN_25 was conducted using Chou and Fasman Secondary Structure Prediction (CFSSP), http://www.biogem.org/tool/chou-fasman/ (Kumar, 2013)

\section{Homology modelling}

The amino acid sequence of haloacid dehalogenase type II from $K$. pneumoniae strain KLPN 25 was submitted to SWISS-MODEL program

at

https://swissmodel.expasy.org/ to obtain a recommended template for three-dimensional structure building (Biasini et al., 2014; Harisna et al., 2017; Waterhouse et al., 2018) and was visualized using PyMol version 2.4.0. The pairwise amino acid sequence alignment between haloacid dehalogenase type II from $K$. pneumoniae strain KLPN_25 and other established templates was conducted using Bioedit version 7.2.5 (Harisna et al., 2017).

\section{RESULTS AND DISCUSSION}

\section{Bacteria growth on 2,2-DCP solid and liquid minimal media}

After 7 days incubation period kept at $30{ }^{\circ} \mathrm{C}$, two colonies were seen on the plate culture (Figure 1). The isolate which has bigger size was streaked again onto fresh 20 $\mathrm{mM}$ 2,2-DCP solid minimal media as sole carbon source to obtain a pure colony. The pure colony of the bacterium was designated as strain $\mathrm{YZ}$.

Since the bacterium strain $Y Z$ isolated from the river water has the ability to grow on a selective media supplemented with $2,2-\mathrm{DCP}$, it is suggested that they are likely to metabolize or utilize $2,2-\mathrm{DCP}$ as a carbon source. The bacterium that can effectively dechlorinates 2,2-DCP as seen in the previous study reported by Jing et al. (2008). Both chloride ions were released from 2,2-DCP and converted into pyruvate. For each molecule of pyruvate formed may be taken as a measure of dehalogenase activity. Apart from turbidity measured at $A_{680 n m}$, the cells growth can be measured by two chloride ions being released from 2,2-DCP.

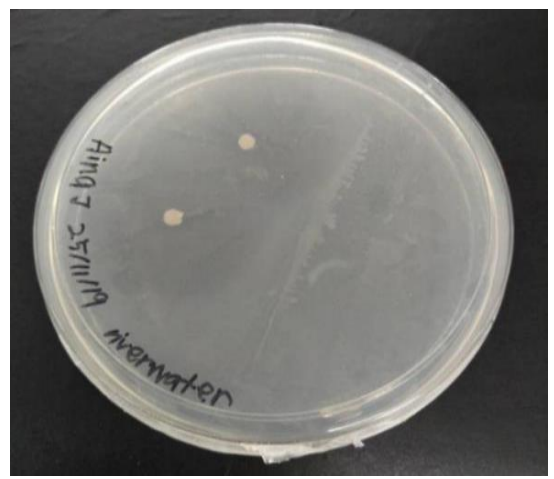

Figure 1: The growth of bacteria on solid minimal media containing $20 \mathrm{mM}$ of 2,2-DCP as a carbon source after 7 days of incubation.

\section{Bacteria growth measurement}

The growth profiles of strain $\mathrm{YZ}$ at different concentrations of 2,2-DCP (10 mM, $20 \mathrm{mM}, 30 \mathrm{mM}$ and $40 \mathrm{mM}$ ) were constructed (Figure 2). The maximum growth was exhibited in $20 \mathrm{mM} 2,2-\mathrm{DCP}$ (A680nm $1.074 \pm 0.04)$ at $16 \mathrm{~h}$ incubation, while no growth was observed at $16 \mathrm{~h}$ in 40 $\mathrm{mM} 2$,2-DCP $(0.190 \pm 0.04)$. This was due to the toxicity effect of the substrate above $40 \mathrm{mM}$ 2,2-DCP to the bacterium, thereby inhibiting growth. Although the bacteria exhibited significant growth at $10 \mathrm{mM}(0.826 \pm$ $0.01)$ and $30 \mathrm{mM}(0.528 \pm 0.01) 2,2-\mathrm{DCP}$, it is still lower compared to $20 \mathrm{mM}$ concentration. The poor growth and/or slow growth of cells could be attributed to several reasons, (i) the poor uptake system of the substrate and (ii) low expression of the dehalogenase gene by the bacteria or (iii) dehalogenase gene system was silent/cryptic due to lack of inducer (Hill et al., 1999). However, it was hypothesized that the lack of growth may possibly be due to the toxicity of the substrate to the bacteria and/or due to the lack of expression of permease uptake system gene, which co-transport the substrate into the cell. It was previously reported that for dehalogenation to occur, the halogen atom of the substrate should fit in a position within the active site that favors its interaction with a basic amino acid residue within the catalytic site for water molecules activation to react with the substrate (Adamu et al., 2020). Therefore, from the results, it shows the optimum concentration of 2,2-DCP to grow and replicate is $20 \mathrm{mM}$, which implying the optimum concentration to degrade the 2,2-DCP is $20 \mathrm{mM}$.

The cells doubling time of strain $Y Z$ in different concentrations of 2,2-DCP were calculated and summarized in the Table 1. The doubling time for strain YZ in $20 \mathrm{mM}$ 2,2-DCP was fastest. It has been reported that Ralstonia solanacearum MK121002 and Chromobacterium violaceum MK121009 (Abel et al., 2012; Ismail et al., 2017) showed an impressive cell

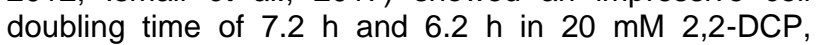
respectively. However, slow growth was observed for Raoutella ornithinolytica (Niknam et al., 2014) and Acinetobacter baumanni MK121007 (Abel et al., 2012) 
with cells doubling time of $23.11 \mathrm{~h}$ in $20 \mathrm{mM}$ 2,2-DCP for both microorganisms, but Citrobacter sp. AZZ2 exhibited a cell doubling time of $15 \mathrm{~h}$ (Hamid et al., 2010). Labrys sp. Wy1 (Wong and Huyop, 2012) and Pseudomonas aeruginosa MX1 (Edbeib et al., 2016) showed a rather longer cells doubling time than any other reported $\alpha$ halogenated compounds degrading microorganisms with reported cells doubling time of $34.6 \mathrm{~h}$ and $44 \mathrm{~h}$, respectively. Nevertheless, both $A$. tumefaciens $\mathrm{RS} 4$, and A. tumefaciens RS5 were found to grow on 2,2-DCP with cells doubling time of 8.5 and $4.7 \mathrm{~h}$, respectively (Schwarze et al., 1997).

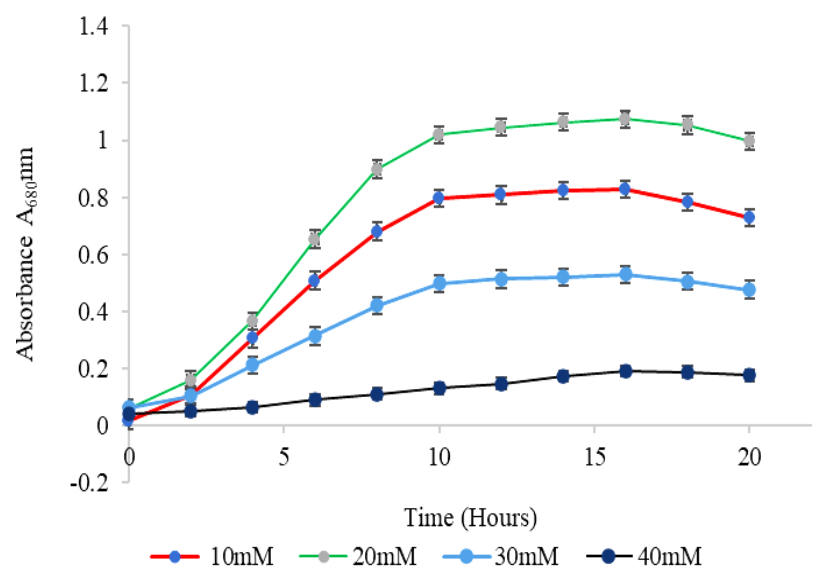

Figure 2: Growth rate of strain $Y Z$ in different concentrations of 2,2-DCP. Readings were taken in triplicates + standard deviation.

Table 1: The doubling time of strain $Y Z$ in different concentrations of 2,2-DCP.

\begin{tabular}{cc}
\hline Concentration $(\mathrm{mM})$ & Doubling time $(\mathrm{h})$ \\
\hline 10 & $9.36 \pm 0.038$ \\
20 & $8.89 \pm 0.030$ \\
30 & $9.75 \pm 0.057$ \\
40 & No growth \\
\hline
\end{tabular}

\section{Morphological observation of isolates}

The morphological and physiological features of strain $Y Z$ were observed following $24 \mathrm{~h}$ of incubation at $30^{\circ} \mathrm{C}$ on 20 $\mathrm{mM}$ of 2,2-DCP solid agar minimal medium. The colony features are summarized in Table 2. The strain $Y Z$ was a Gram-negative bacterium with rod shape (Figure 3).

\section{Biochemical characterization and bacterium identification}

The API-20E for strain YZ was summarized in Table 3. The results were compared with Bergey's Manual of Systematic Bacteriology (Holt et al., 1994) in order to identify the genus and species of the strain $Y Z$. The
Table 2: Colony observations of strain $Y Z$ on $20 \mathrm{mM}$ of 2,2-DCP solid minimal media over $24 \mathrm{~h}$.

\begin{tabular}{ll}
\hline Parameters & Results \\
\hline Pigmentation (pure colony) & creamy \\
Margin & entire \\
Colour & milky \\
Elevation & convex \\
Texture & mucoid \\
Shape & punctiform \\
\hline
\end{tabular}

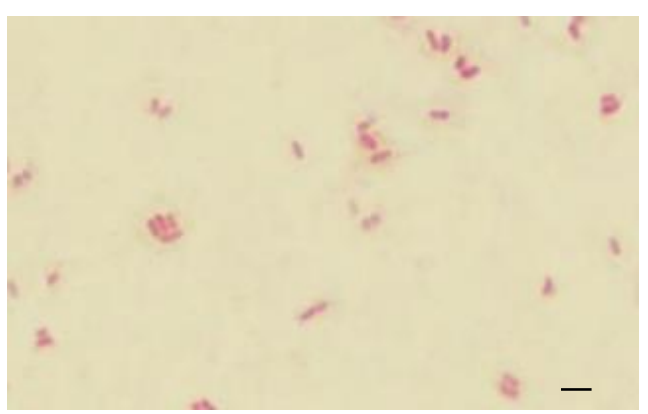

Figure 3: Strain $Y Z$ was observed under 1000x magnification using light microscope. The bacteria were Gram-negative, rod in shape. Scale bar (-) in the figure indicates $2 \mu \mathrm{m}$ length.

biochemical tests were selected based on the Gramnegative bacteria and non-motile. According to the previous study, Klebsiella sp. have typical Gram-negative bacilli characteristics with citrate, oxidase, urease and indole positive as well as non-motile (Alves et al., 2006). In addition, Klebsiella sp. have shown catalase positive and formed pink colonies indicating the fermentation of lactose on MacConkey agar (Patel et al., 2017). Meanwhile, negative result was shown in starch hydrolysis test for Klebsiella sp. (Kumar et al., 2019). Based on current API-20E biochemical characteristics results, it was proposed strain $Y Z$ belongs to $K$. pneumoniae. An API-20E was applied in this study for rapid identification of the bacteria from total bacterial population. The test sensitive enough for the identification of microorganisms up to the genus and species level (Juang and Morgan, 2001; O'hara, 2005). However, in future an additional method like 16S rRNA may be necessary.

Klebsiella sp. belongs to the family Enterobacteriaceae which is widely found in nature (soil, plants, waters) and in the gastrointestinal tracts of a wide range of animals. Klebsiella sp. is usually involved in nosocomial infections, such as urinary and respiratory tract infections as well as infections of wounds and soft tissue (Herridge et al., 2020). Klebsiella pneumoniae and Klebsiella oxytoca are the most common pathogens in genus Klebsiella that have rapidly become global threat. Apart from their pathogenicity properties, Klebsiella sp. have been reported in utilizing or degrading hydrocarbons (Ismail et al., 2017). The influence of organic fertilizers on the bioremediation of hydrocarbon-contaminated soil was 
previously studied and Klebsiella sp. was found as the isolated microorganism (Ibiene et al., 2011). This shows that genus Klebsiella sp. has the ability to perform bioremediation.

Database search of genome sequence belongs to $K$. pneumoniae KLPN_25

Since the current isolated bacteria which proposed as $K$. pneumoniae strain $\mathrm{YZ}$ was able to grow in minimal media supplemented with 2,2-DCP as sole source of carbon and energy, therefore, it was hypothesized that strain $\mathrm{YZ}$ contain dehalogenase gene. Genomic content of the same genus and species might contain similar DNAs and some other properties. Hence, the NCBI database search was carried out to observe whether any other $K$. pneumoniae that have its full genome sequence to screen for the presence of dehalogenase gene(s).

The genomic sequence of $K$. pneumoniae strain KLPN_25 with database number of RCZV01000004 (Tamma et al., 2018) was selected from NCBI and was further analysed. In this study, only one haloacid dehalogenase type II (deh type II) gene from $K$. pneumoniae strain KLPN_25 was detected from its full genome sequence with accession number RRE04903. The corresponding dehalogenase gene FASTA format was then converted into its amino acid sequence for further protein analysis.

Table 3: API-E20 biochemical tests result for strain YZ.

\begin{tabular}{lc}
\hline Tests & Results \\
\hline Catalase & positive \\
Ornithine decarboxylase test & negative \\
Lactose utilization & positive \\
Citrate & positive \\
Oxidase & positive \\
Urease & positive \\
Indole & negative \\
Methyl-red test & negative \\
Voges-Proskauer test & positive \\
Hydrogen sulfide production (TSI) & negative \\
Urea hydrolysis test & positive \\
Lysine decarboxylase test & positive \\
D-Glucose (acid/gas) & positive/ positive \\
D-mannitol fermentation & positive \\
Sucrose fermentation & positive \\
Arginine dihydrolase test & negative \\
D-sorbitol fermentation & positive \\
Cellobiose & positive \\
Esculin hydrolysis & positive \\
ONPG Test & positive \\
\hline
\end{tabular}

\section{Computational studies}

Computational analysis of haloacid dehalogenase type II from $K$. pneumoniae strain KLPN_25 have been carried out and its amino acid sequence was compared to other sequences in NCBI database using BLASTp. The amino acid sequence showed homology with various dehalogenase amino acid sequences from other bacterial species as summarized in Table 4.

\section{Primary structure analysis}

The primary structure of dehalogenase type II from $K$. pneumoniae strain KLPN_25 was generated using Protparam tool. The protein sequence consists of 235 amino acid residues with molecular weight of 25,595.05 $\mathrm{Da}$ with a positive GRAVY value (grand average of hydrophobicity) of 0.003 . This indicates that dehalogenase type II was hydrophobic. The theoretical isoelectric point $(\mathrm{pl})$ of dehalogenase type II was 4.85 suggesting its acidic amino acids were more than basic amino acids. There was a total of 30 negatively charged and 19 positively charged residues in the amino acid sequence. Furthermore, the total number of atoms was 3591 with a molecular formula of $\mathrm{C}_{1143} \mathrm{H}_{1790} \mathrm{~N}_{298} \mathrm{O}_{352} \mathrm{~S}_{8}$ and aliphatic index of 93.91 .

\section{Multiple sequence alignment}

The multiple sequence alignment of dehalogenase type II amino acid from five different species were performed as shown in Figure 4. This alignment has a minimum sequence length of 151 amino acid from Klebsiella michiganensis and a maximum sequence length of 235 from Enterobacteriaceae and Salmonella enterica subsp. enterica. Both $K$. pneumoniae strain KLPN_25 and Pantoea deleyi have a sequence length of 231, while $P$. ananatis has a sequence length of 226 amino acid. The multiple sequence alignment provides information on the conservation of core residues, includes hydrophobic core residues and regions that are important for protein function. The amino acids residues highlighted in red colour are the amino acid residues with high consensus and those low consensus value and neutral are in black. The conserved regions are G (Gly12), (Gly67), (Gly82), (Gly108), (Gly116), L (Leu14), (Leu22), (Leu23), (Leu28), (Leu36), (Leu51), (Leu55), (Leu74), (Leu85), (Leu92), (Leu109), (Leu112), (Leu119), (Leu122), (Leu134), (Leu147), F (Phe15), (Phe16), (Phe47), (Phe66), (Phe143), D (Asp17), (Asp24), (Asp104), V (Val18), (Val56), (Val59), (Val73), (Val105), (Val120), (Val149), N (Asn19), (Asn124), E (Glu20), (Glu71), (Glu75), (Glu87), (Glu150), T (Thr21), (Thr48), (Thr60), (Thr77), (Thr123), R (Arg35), (Arg39), (Arg80), W (Trp46), S (Ser49), (Ser54), (Ser62), (Ser125), (Ser148), H (His52), (His64), (His102), I (lle69), (lle83), A(Ala70), (Ala72), (Ala78), (Ala101), (Ala106), (Ala121), (Ala127), (Ala130), (Ala137), M (Met76), Y (Tyr81), P (Pro100), (Pro103) and Q (Gln114), (Gln115), (Gln133).

\section{Secondary structure prediction}

The prediction of the secondary structure of the protein done using CFSSP program showed that the number of predicted quantities of amino acid residues to form helix structure $(\mathrm{H})$ are 195 equals to $83 \%$, while 150 amino 
Malays. J. Microbiol. Vol 17(3) 2021, pp. 294-304

DOI: http://dx.doi.org/10.21161/mjm.201012

Table 4: List of dehalogenases enzyme and its sources.

\begin{tabular}{|c|c|c|c|c|}
\hline Organism & Dehalogenase & $\begin{array}{c}\text { Accession } \\
\text { number }\end{array}$ & $\begin{array}{l}\text { Percentage } \\
\text { identity }\end{array}$ & References \\
\hline $\begin{array}{l}\text { Multispecies: } \\
\text { Enterobacteriaceae }\end{array}$ & Deh type II & WP_040063703 & $100.00 \%$ & $\begin{array}{l}\text { (van der Ploeg et al., 1991; Hill et al., } \\
\text { 1999; Tsang and Sam, 1999; Janssen, } \\
\text { 2001) }\end{array}$ \\
\hline $\begin{array}{l}\text { S. enterica subsp. } \\
\text { enterica }\end{array}$ & Deh type II & EBH2621797 & $99.57 \%$ & $\begin{array}{l}\text { Unpublished } \\
\text { https://www.ncbi.nlm.nih.gov/protein/E } \\
\text { BH2621797.1 }\end{array}$ \\
\hline$P$. ananatis & Deh type II & WP_024472286 & $72.32 \%$ & $\begin{array}{l}\text { (van der Ploeg et al., 1991; Hill et al., } \\
\text { 1999; Tsang and Sam, 1999; Janssen, } \\
\text { 2001) }\end{array}$ \\
\hline K. michiganensis & Deh type II & PLL41259 & $100.00 \%$ & (Yang et al., 2019) \\
\hline P. deleyi & Deh type II & WP_128086185 & $63.48 \%$ & $\begin{array}{l}\text { (van der Ploeg et al., 1991; Hill et al., } \\
\text { 1999; Tsang and Sam, 1999; Janssen, } \\
\text { 2001) }\end{array}$ \\
\hline
\end{tabular}
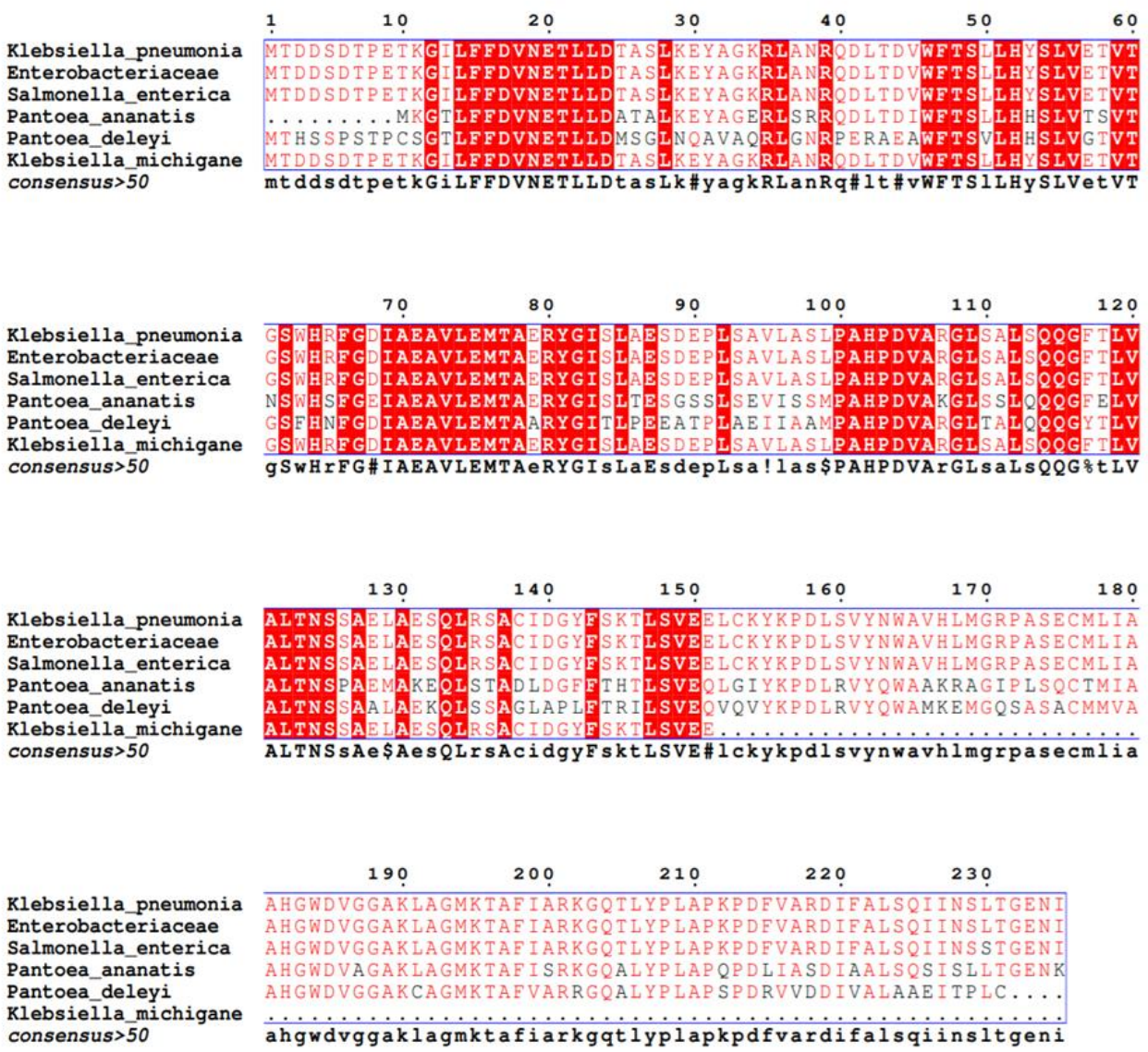

Figure 4: Multiple sequence alignment of haloacid dehalogenase type II from K. pneumoniae strain KLPN_25 with other five sequence from different species. The alignment was generated by MultiAlin program. Conserved amino acids residues are D (Asp), R (Arg), S (Ser), H (His), I (lle), A (Ala), M (Met), Y (Tyr), P (Pro) and Q (Gln). The sequence were downloaded with accession number: K. pneumoniae strain KLPN_25 (RRE04903) (Tamma et al., 2018), Enterobacteriaceae (WP_040063703) (van der Ploeg et al., 1991; Hill et al., 1999; Tsang and Sam, 1999; Janssen, 2001), S. enterica subsp. enterica (EBH2621797), P. ananatis (WP 024472286) (van der Ploeg et al., 1991; Hill et al., 1999; Tsang and Sam, 1999; Janssen, 2001), P. deleyi (WP_128086185) (van der Ploeg et al., 1991; Hill et al., 1999; Tsang and Sam, 1999; Janssen, 2001) and K. michiganensis (PLL41259) (Yang et al., 2019). 
Malays. J. Microbiol. Vol 17(3) 2021, pp. 294-304

DOI: http://dx.doi.org/10.21161/mjm.201012

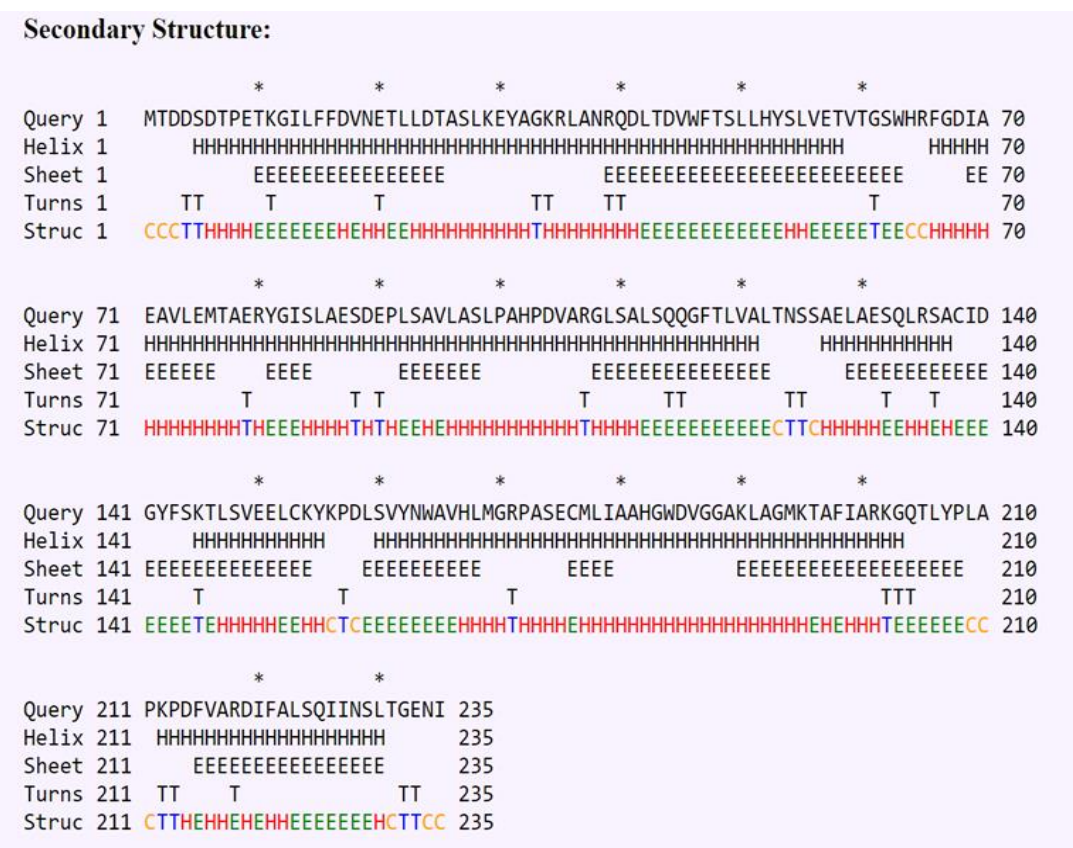

Figure 5: Prediction of the secondary structure of haloacid dehalogenase type II from K. pneumoniae strain KLPN_25.

acid residues form beta sheet (E), (63.8\%) and 30 amino acids residue form turns $(\mathrm{T}),(12.8 \%)$ as shown in Figure 5 . This predicted secondary structure of Deh type II by CFSSP server is in agreement for construction of homology model using SWISS-MODEL, whereby the enzyme is mainly made up from alpha helices and beta sheets but the loops are also significant.

\section{Homology modelling}

In the present study, three-dimensional model of dehalogenase type II from $K$. pneumoniae strain KLPN_25 was constructed based on the suggested template L-2-haloacid dehalogenase (L-DEX) from Pseudomonas sp. strain YL (PDB ID: 1JUD) by using SWISS-MODEL, a modelling server as shown in Figure 6. The template possesses $23.64 \%$ of sequence identity, 0.33 of sequence similarity and a coverage score of 0.94 . The predicted structural model showed the "Global Model Quality Estimation" (GMQE) value of 0.61 and "Qualitative Model Energy Analysis" (QMEAN) is -3.27. GMQE is a parameter in estimating the model quality based on the target-template alignment and the template search method, ranging from 0 to 1 (Benkert et al., 2008). The model built for dehalogenase type II from $K$. pneumoniae strain KLPN 25 based on the template L-DEX from Pseudomonas sp. strain YL reflects a considerably high in reliability with a 0.61 score in the expected accuracy of a model built with that alignment and template. On the other hand, QMEAN score indicates an estimation of the "degree of nativeness" of the structural features observed in the model on a global scale, in which the score around zero suggests good agreement between the model structure and experimental structures of similar size while a score of -4.0 or lower is an indication of model with low quality (Benkert et al., 2008). Therefore, the model built with -3.27 QMEAN score is still considered quite good in the quality.

\section{Pairwise analysis}

The pairwise of both dehalogenase type II from $K$. pneumoniae strain KLPN_25 and L-DEX from Pseudomonas sp. strain YL showed only $24 \%$ sequence identity (41\% similarity), however, some important amino acids are compared as well, for example D (Asp10), T (Thr14), R (Arg41), S (Ser118), K (Lys151), Y (Tyr157), S (Ser175), N (Asn177), and D (Asp180) (Figure 7). These are key amino acid residues that important for catalysis in the crystallised dehalogenases of L-DEX strain YL. In this study, these amino acids were predicted to have similar function with dehalogenase type II KLPN_25. The L-DEX YL amino acids are best aligned at location Asp10, Thr14, Arg41, Ser118, Lys151, Tyr157 and D180 are relatively equivalent to Asp17, Thr21, Arg39, Ser125, Lys156, Tyr162 and Asp185, respectively. Conserved amino acid residues often provide functional conservation. Therefore, it can be hypothesized that the catalytically important residues of L-DEX YL that are conserved dehalogenase type II KLPN_25 may also be catalytically important and probably have similar functions.

The key amino acids Asp10 in L-DEX YL (Asp17 in dehalogenase type II KLPN_25) have shown to play a role as a nucleophile $\alpha$-carbon of the substrate to form an ester intermediate in the L-haloacid dehalogenase mechanism (Kondo et al., 2015). The role of Thr14 in LDEX YL (Thr21 in dehalogenase type II), is not yet 


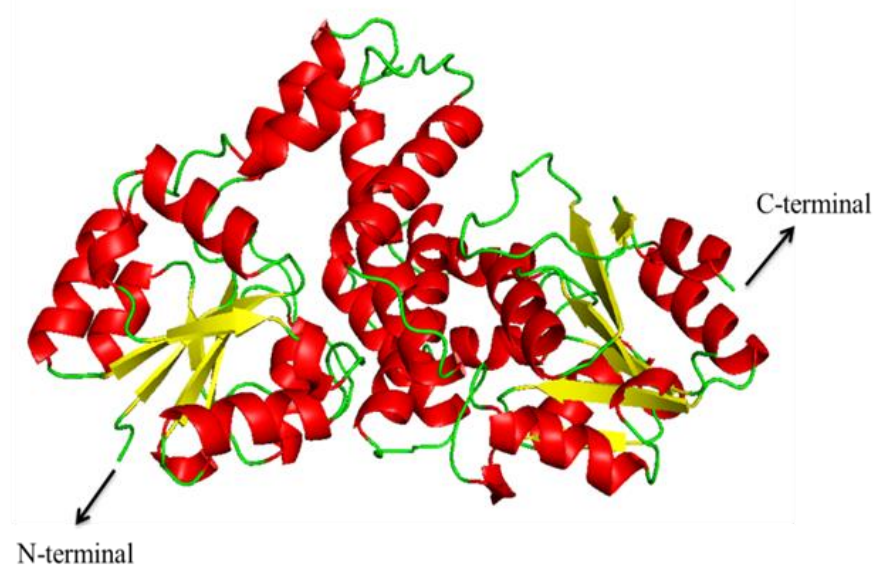

Figure 6: The structure of dehalogenase type II from K. pneumoniae strain KLPN_25 built according to L-DEX from Pseudomonas sp. strain YL as a template showing its secondary structures consisting of $\alpha$-helix (red), $\beta$-sheet (yellow) and loop (green).
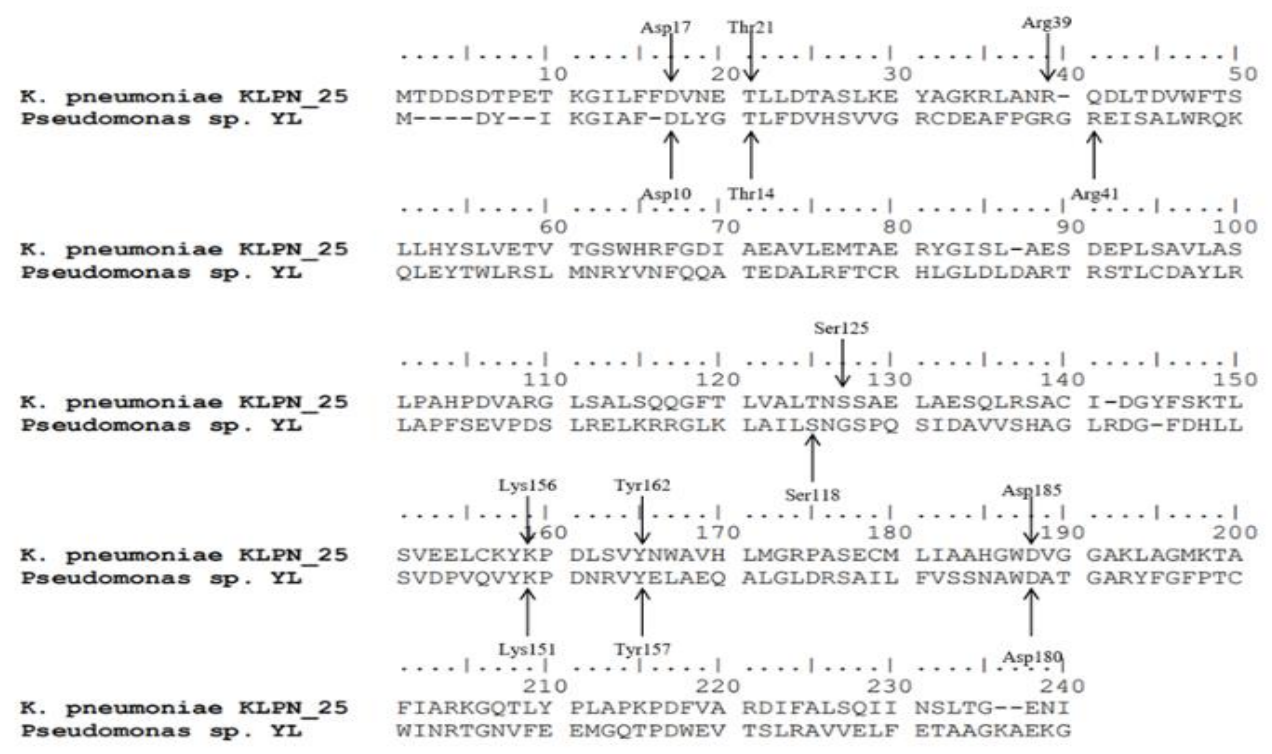

Figure 7: The pairwise sequence alignment results within haloacid dehalogenase type II from $K$. pneumoniae strain KLPN_25 and L-DEX from Pseudomonas sp. strain YL. Conserved regions are D (Asp17), T (Thr21), R (Arg39), S (Ser125), K (Lys156), Y (Tyr162) and D (Asp185).

determined, however it was reported to firmly hold the Asp10 in a position that favours the nucleophilic attack (Ridder et al., 1997). Arg41 in L-DEX YL which corresponds to Arg39 in dehalogenase type II KLPN_25 act as a substrate uptake, by accepting the chloride ion released (Adamu et al., 2016). Ser118 in L-DEX YL (Ser125 in dehalogenase type II KLPN_25) acts to stabilize the substrate hydrolysis of ester carboxyl moiety (Harisna et al., 2017). In addition, Lys151 and Tyr157 in L-DEX YL corresponds with Lys156 and Tyr162 in dehalogenase type II KLPN_25, are proposed to be hydrogen-bonded to Asp180, in order for Asp180 keeps the orientation to activate the water molecule (Hisano et al., 1996). Furthermore, Asp180 in L-DEX (Asp185 in dehalogenase type II), activate the hydrolysis of ester intermediate.

On the other hand, another two catalytically important residues of L-DEX YL which are S175 and N177, are not conserved in dehalogenase type II KLPN_25 and may probably the same as those in L-DEX but in different positions in the active site or substituted by similar residues. To fully elucidate the dehalogenation 
mechanism of dehalogenase type II from $K$. pneumoniae strain KLPN_25 and the contributions of the specific residues, additional work is needed. Although, dehalogenase type II KLPN_25 might dehalogenates the same substrates as L-2-haloacid dehalogenases from other organisms, its overall amino acid sequence is quite different from those of the other enzymes. Results of our pairwise and structural superposition of dehalogenase type II KLPN_25 amino acid sequence comparison with LDEX from $\bar{P}$ seudomonas sp. strain $\mathrm{YL}$ suggest that Asp17, Thr21, Arg39, Ser125, Lys156, Tyr162 and Asp185 are conserved in dehalogenase type II KLPN_25 and may be catalytically important in dehalogenation reaction.

\section{CONCLUSION}

Current study focused on isolation and characterization of bacteria able to utilize 2,2-DCP as a sole carbon source, a model substrate to detect the presence of dehalogenases. A bacterium strain $Y Z$ was successfully isolated from the river water sample of Sungai Skudai, Johor. The bacterium grown well in both liquid and solid PJC minimal media containing $10 \mathrm{mM}, 20 \mathrm{mM}$ and $30 \mathrm{mM}$ 2,2-DCP, but growth was inhibited at $40 \mathrm{mM}$ of 2,2-DCP. The biochemical tests and morphological examination revealed that bacteria strain $\mathrm{YZ}$ shared similarity with $K$. pneumoniae. The isolated bacterium was designated as K. pneumoniae strain YZ. Genomic DNA (obtained from NCBI data bases) of $K$. pneumoniae strain KLPN_25 was further analysed assuming strain $Y Z$ and KLPN_25 strains carried similar gene functions. Dehalogenase gene type II was found in strain KLPN_25. A threedimensional model of haloacid dehalogenase type II from K. pneumoniae strain KLPN_25 was constructed based on template L-DEX from Pseudomonas sp. strain YL with conserved amino acid residues that play important roles in dehalogenation process. It is hypothesized that dehalogenase type II of $K$. pneumoniae strain KLPN_25 may have similar functions with crystallized L-DEX from Pseudomonas sp. strain $\mathrm{YL}$, which is also present in strain $\mathrm{YZ}$.

\section{ACKNOWLEDGEMENTS}

We are grateful to the Fundamental Research Grant Scheme (FRGS) R.J130000.7854.5F189FRGS/1/2019/STG05/UTM/01/1 (Ministry of Higher Education Malaysia), RUG-UTM-HRQ.J130000.2414.08G59 (Universiti Teknologi Malaysia) and the Universiti Malaysia Sabah for partially funding the research materials.

\section{REFERENCES}

Abel, E., Pakingking Jr., R. V., Pagador, G., Wint, M. T. and Huyop, F. (2012). Characteristics of dehalogenase from bacteria isolated from the gut of pond reared rohu (Labeo rohita) juveniles in Myanmar.
Advances in Bioscience and Biotechnology 3(4), 353361.

Adamu, A., Wahab, R. A. and Huyop, F. (2016). L-2Haloacid dehalogenase (DehL) from Rhizobium $\mathrm{sp.}$ RC1. Springerplus 5(1), 695.

Adamu, A., Wahab, R. Ab., Aliyu, F., Aminu, A. H., Hamza, M. M. and Huyop, F. (2020). Haloacid dehalogenases of Rhizobium sp. and related enzymes: Catalytic properties and mechanistic analysis. Process Biochemistry 92, 437-446.

Alomar, D., Hamid, A. A. A., Khosrowabadi, E., Gicana, R. G., Lamis, R. J. and Huyop, F. (2014). Molecular characterization of monochloroacetatedegrading Arthrobacter sp. strain d2 isolated from Universiti Teknologi Malaysia agricultural area. Bioremediation Journal 18(1), 12-19.

Altschul, S., Gish, W., Miller, W., Myers, E. and Lipman, D. (1990). Basic local alignment search tool. Journal of Molecular Biology 215(3), 403-410.

Amini, S., Zulkifly, A. H., Wen-Yong, W. and Huyop, F. (2011). Molecular identification and characterization of a bacterium that has potential to degrade low concentration of haloalkanoic acid. Journal of Microbiology Research 6(6), 552-559.

Alves, M. S., Dias, R. C. S., de Castro, A. C. D., Riley, L. W. and Moreira, B. M. (2006). Identification of clinical Isolates of Indole-positive and Indole-negative Klebsiella spp. Journal of Clinical Microbiology 44(10), 3640-3646.

Bagherbaigi, S., Gicana, R. G., Lamis, R. J., Nemati, $M$. and Huyop, F. (2013). Characterisation of Arthrobacter sp. S1 that can degrade $\alpha$ and $\beta$ haloalkanoic acids isolated from contaminated soil. Annals of Microbiology 63(4), 1363-1369.

Benkert, P., Tosatto, S. C. E. and Schomburg, D. (2008). Qmean: A comprehensive scoring function for model quality assessment. Proteins: Structure, Function, and Bioinformatics 71, 261-277.

Biasini, M., Bienert, S., Waterhouse, A., Arnold, K., Studer, G., Schmidt, T., Kiefer, F., Cassarino, T. G., Bertoni, M., Bordoli, L. and Schwede, T. (2014). Swiss-model: Modelling protein tertiary and quaternary structure using evolutionary information. Nucleic Acids Research 42, W252-258.

Corpet, F. (1988). Multiple sequence alignment with hierarchical clustering. Nucleic Acids Research 16(22), 10881-10890.

Edbeib, M. A., Wahab, R. and Huyop, F. (2016). Characterization of an a-haloalkanoic acid-degrading Pseudomonas aeruginosa MX1 isolated from contaminated seawater. Bioremediation Journal 20(2), 89-97.

Fetzner, S. (1998). Bacterial dehalogenation. Applied Microbiology and Biotechnology 50(6), 633-657.

Fetzner, S. and Lingens, F. (1994). Bacterial dehalogenases: Biochemistry, genetics, and biotechnological applications. Microbiological Reviews 58(4), 641-685.

Gasteiger, E., Hoogland, C., Gattiker, A., Duvaud, S., Wilkins, M. R., Appel, R. D. and Bairoch, A. (2005). 
Protein identification and analysis tools on the expasy server. In: The Proteomics Protocols Handbook. Walker, J. M. (ed.). Humana Press, Totowa, New Jersey. pp. 571-607.

Hamid, A. A., Hamdan, S., Ariffn, S. H. and Huyop, F. (2010). Molecular prediction of dehalogenase producing microorganism using $16 \mathrm{~S}$ rDNA analysis of 2, 2-dichloropropionate (Dalapon) degrading bacterium isolated from volcanic soil. Journal of Biological Sciences 10(3), 190-199.

Hamid, T. A., Haziyamin, T., Hamid, A., Zulkifly, N. A. H., Hamdan, S., Ariffin, S. H. Z. and Huyop, F. (2011). Purification and properties of a new dehalogenase enzyme from Pseudomonas sp. B6P grow in 3-chloropropionate (3CP). African Journal of Biotechnology 10(24), 610-614.

Hareland, W. A., Crawford, R. L., Chapman, P. J. and Dagley, S. (1975). Metabolic function and properties of 4-hydroxyphenylacetic acid 1-hydroxylase from Pseudomonas acidovorans. Journal of Bacteriology 121(1), 272-285.

Harisna, A. H., Edbeib, M. F., Adamu, A., Hamid, A. A. A., Wahab, R. A., Widodo. and Huyop, F. (2017). In silico molecular analysis of novel L-specific dehalogenase from Rhizobium sp. RC1. Malaysian Journal of Microbiology 3(1), 50-60.

Heidarrezaei, M., Shokravi, H., Huyop, F., Koloor, S. S. R. and Petrů, M. (2020). Isolation and characterization of a novel bacterium from the marine environment for trichloroacetic acid bioremediation. Applied Sciences 10(13), 4593.

Herridge, W. P., Shibu, P., O'Shea, J., Brook, T. C. and Hoyles, L. (2020). Bacteriophages of Klebsiella spp., their diversity and potential therapeutic uses. Journal of Medical Microbiology 69(2), 176-194.

Hill, K. E., Marchesi, J. R. and Weightman, A. J. (1999). Investigation of two evolutionarily unrelated halocarboxylic acid dehalogenasegene families. Journal of Bacteriology 181(8), 2535-2547.

Hisano, T., Hata, Y., Fujii, T., Liu, J. Q., Kurihara, T., Esaki, N. and Soda, K. (1996). Crystallization and preliminary X-ray crystallographic studies of I-2haloacid dehalogenase from Pseudomonas sp. YL. Proteins: Structure, Function and Genetics 24(4), 520522.

Holt, J. G., Krieg, N. R., Sneath, P. H. A. and Staley, J. T. and Williams, S. T. (1994). Bergey's Manual of Determinative Bacteriology. 9th Edn. Williams and Wilkins, Baltimore, United Sataes. pp.527-528.

Huyop, F. and Nemati, M. (2010). Properties of dehalogenase from Rhizobium sp. RC1. African Journal of Microbiology Research 4(25), 2836-2847.

Ibiene, A. A., Orji, F. A., Ezidi, C. O. and Ngwobia, C. L. (2011). Bioremediation of hydrocarbon contaminated soil in the Niger Delta using spent mushroom compost and other organic wastes. Nigerian Journal of Agriculture, Food and Environment 7(3), 1-7.

Ismail, S. N. F., Wahab, R. A. and Huyop, F. (2016). Isolation and identification of bacteria isolated from ruminant animal waste that able to degrade 2,2- dichloropropionic acid (2,2-DCP). Malaysian Journal of Microbiology 12(2), 155-163.

Ismail, S. N. F., Wahab, R. A. and Huyop, F. (2017). Microbial isolation and degradation of selected haloalkanoic aliphatic acids by locally isolated bacteria: A review. Malaysian Journal of Microbiology 13(3), 261-272.

Janssen, D. B., Oppentocht, J. E. and Poelarends, G. J. (2001). Microbial dehalogenation. Current Opinion in Biotechnology 12(3), 254-258.

Jing, N. H. and Huyop, F. (2008). Enzymatic dehalogenation of 2,2-dichloropropionic acid by locally isolated Methylobacterium sp. HJ1. Journal of Biological Science 8(1), 233-235.

Jing, N. H., Taha, A. M., Pakingking Jr., R. V., Wahab, R. Ab. and Huyop, F. (2008) Dehalogenase from Methylobacterium sp. HJ1 induced by the herbicide 2, 2-dichloropropionate (Dalapon). African Journal of Microbiology Research 2, 32-36.

Juang, D. E. and Morgan, J. E. (2001). The applicability of the API 20E and API Rapid NFT systems for the identification of bacteria from activated sludge. Electronic Journal of Biotechnology 4(1), 1-7.

Kondo, H., Fujimoto, K. J., Tanaka, S., Deki, H. and Nakamura, T. (2015). Theoretical prediction and experimental verification on enantioselectivity of haloacid dehalogenase L-DEX YL with chloropropionate. Chemical Physics Letters 623, 101107.

Kumar, T. A. (2013). CFSSP: Chou and Fasman Secondary Structure Prediction server. Wide Spectrum Research Journal 1(19),15-19.

Kumar, K. M. A., Chandan, S. and Puttaiah, S. H. (2019). Potential antimicrobial and antioxidant activity of Saraca indica and Cleodendrum paniculatum from Western Ghats, Shimoga, India. International Journal of Environmental Health and Technology 1(3), 91-99.

Niknam, M., Huyop, F. and Wahab, R. Ab. (2014). Identification and characterization of Raoutella ornithilolytica and determination of its herbicide 2,2dichloropropionate (2,2-DCP) degradation potential. Malaysian Journal of Microbiology 10, 249-254.

O'hara, C. M. (2005). Manual and automated instrumentation for identification of Enterobacteriaceae and other aerobic Gram-negative bacilli. Clinical Microbiology Reviews 18(1), 147-162.

Oyewusi, H. A., Wahab, R. A., Kaya, Y., Edbeib, M. F. and Huyop, F. (2020) Alternative bioremediation agents against haloacids, haloacetates and chlorpyrifos using novel halogen-degrading bacterial isolates from the hypersaline Lake Tuz. Catalysts 10(6), 651.

Oyewusi, H. A., Wahab, R. A., Edbeib, M. F., Mohamad, M. A. N., Hamid, A. A. A., Kaya, Y. and Huyop, F. (2021) Functional profiling of bacterial communities in Lake Tuz using 16S rRNA gene sequences. Biotechnology and Biotechnological Equipment 35(1), 1-10.

Patel, S. S., Chauhan, H. C., Patel, A. C., Shrimali, M. D., Patel, K. B., Prajapati, B. I., Kala, J. K., Patel, M. 
G., Rajgor, M. and Patel, M. A. (2017). Isolation and identification of Klebsiella pneumoniae from sheepcase report. International Journal of Current Microbiology and Applied Sciences 6(5), 331-334.

Ridder, I. S., Rozeboom, H. J., Kalk, K. H., Janssen, D. B. and Dijkstra, B. W. (1997). Three-dimensional structure of 1-2-Haloacid dehalogenase from Xanthobacter autotrophicus GJ10 complexed with the substrate-analogue formate. Journal of Biological Chemistry 272(52), 33015-33022.

Schwarze, R., Brokamp, A. and Schmidt, F. R. (1997). Isolation and characterization of dehalogenases from 2,2-dichloropropionate-degrading soil bacteria. Current Microbiology 34(2), 103-109.

Tamma, P. D., Fan, Y., Bergman, Y., Pertea, G., Kazmi, A., Lewis, S., Carroll, K. C., Schatz, M. C., Timp, W. and Simner, P. J. (2018). Applying rapid whole genome sequencing to predict phenotypic antimicrobial susceptibility testing results among carbapenem-resistant Klebsiella pneumoniae clinical isolates. Antimicrobial Agents and Chemotherapy 63(1), 1-12.

Tsang, J. and Sam, L. (1999). Cloning and characterization of a cryptic haloacid dehalogenase from Burkholderia cepacia MBA4. Journal of Bacteriology 181(19), 6003-6009.

van der Ploeg, J., van Hall, G. and Janssen, D. (1991). Characterization of the haloacid dehalogenase from Xanthobacter autotrophicus GJ10 and sequencing of the dhIB gene. Journal of Bacteriology 173(24), 79257933.

Wahhab, B. H. A., Samsulrizal, N. H., Edbeib, M. F., Wahab, R. A., Al-Nimer, M. S. M., Hamid, A. A. A., Oyewusi, H. A., Kaya, Y., Notarte, K. I. R., Shariff A. H. M. and Huyop, F. (2021). Genomic analysis of functional haloacid-degrading gene of Bacillus megaterium strain BHS1 isolated from Blue Lake (Mavi Göl, Turkey). Annals of Microbiology 71(12), 111.

Waterhouse, A., Bertoni, M., Bienert, S., Studer, G., Tauriello, G., Gumienny, R., Heer, F. T., de Beer, T. A. P., Rempfer, C., Bordoli, L., Lepore, R. and Schwede, T. (2018). SWISS-MODEL: Homology modelling of protein structures and complexes. Nucleic Acids Research 46(1), 296-303.

Wong, W. Y. and Huyop, F. (2012). Molecular identification and characterization of Dalapon-2,2dichloropropionate (2,2-DCP)-degrading bacteria from a rubber estate agricultural area. African Journal of Microbiology Research 6(7), 1520-1526.

Yang, Y., Higgins, C. H., Rehman, I., Galvao, K. N., Brito, I. L., Bicalho, M. L., Song, J., Wang, H. and Bicalho, R. C. (2019). Genomic diversity, virulence, and antimicrobial resistance of Klebsiella pneumoniae strains from cows and humans. Applied and Environmental Microbiology 85 (6), 1-12. 